\title{
WHU蚺
}

Otto Beisheim School of Management

\section{Do Current Account Forecasters Herd? - Evidence from the Euro Area and the $\mathrm{G} 7$ Countries}

Michael Frenkel

WHU - Otto Beisheim

School of Management

michael.frenkel@whu.edu
Jan Christoph Rülke

WHU- Otto Beisheim School of Management jan-c.ruelke@whu.edu

\section{Lilli Zimmermann}

WHU - Otto Beisheim

School of Management

lilli.zimmermann@whu.edu

WHU - Working Paper

Series in Economics

WP 11/01 


\title{
Do Current Account Forecasters Herd? - Evidence from the Euro Area and the G7 Countries*
}

\author{
Michael Frenkel, Jan-Christoph Rülke, and Lilli Zimmermann
}

\begin{abstract}
We use data from the Consensus Economics Forecast Poll to analyze how current account forecasters form expectations. Our results suggest that forecasts do not satisfy traditional unbiasedness and orthogonality criteria for forecast rationality. In addition, we find anti-herding behavior among forecasters for the euro area and G7 countries. We also show that the cross-sectional heterogeneity in anti-herding is associated with cross-sectional heterogeneity in forecast accuracy. More specifically, we find some evidence indicating that forecasters who tend to herd provide more accurate forecasts than their colleagues who follow an anti-herding strategy.
\end{abstract}

${ }^{*}$ Frenkel, Rülke, Zimmermann: WHU - Otto Beisheim School of Management, Burgplatz 2, 56179 Vallendar, Germany. We are grateful to an anonymous referee for helpful comments and suggestions. We thank Maritza Frenkel for copy-editing the manuscript. All remaining errors are the sole responsibility of the authors.

JEL Classification Number(s): F17, D84, C33

Address of Contact Author: WHU - Otto Beisheim School of Management, Burgplatz 2, 56179 Vallendar, Germany. Phone: +49 (0) 261-6509-286; Fax: +49 (0) 261-6509-289; E-mail: jan-c.ruelke@whu.edu 


\section{Introduction}

During the past decade, global external imbalances have received considerable attention by both economists and politicians. The sizable U.S. current account deficit in particular has renewed academic discussions on the possible risks to macroeconomic and financial stability stemming from current account deficits and the ensuing build-up of international liabilities. In this context, a number of theories have been advanced explaining the interlinkages between global external imbalances and the financial and economic crisis of 2008/2009. Caballero et al. (2008) argue that the large capital flows from Asia to the U.S. which were motivated by storing value in relatively safe and liquid financial markets, significantly contributed to the worsening of lending and regulatory standards which ultimately triggered the crisis. Therefore, an assessment of global current account positions appears to be very important.

Temporal current account imbalances both deficits and surpluses are regarded as neither good nor bad but as a mere reflection of differences in cyclical and structural factors between economies. However, unsustainable and persistent current account imbalances, particularly in the form of deficits, can eventually create the need for considerable economic adjustment involving painful economic changes in many cases (Berger et al., 2008; Chinn and Ito, 2008; Engler et al., 2009). Several studies of reversals of current account deficits show that the adjustment process typically includes a significant real depreciation of the domestic currency and a slowdown in real GDP growth, private consumption, and investment (Milesi-Ferretti and Razin, 1998; McKinnon, 2001; Freund, 2005; De Haan et al., 2008). Hence, it is important for policymakers, financial market participants, and researchers alike to focus on the current account as a crucial macroeconomic variable. Moreover, policymakers are 
better prepared for frictions resulting from adjustment measures, when they can anticipate such necessary changes. Market expectations - if accurate - can be early indicators of these changes (Eijffinger and Goderis, 2007).

In this respect, especially forecasts of or expectations about current account movements can provide valuable information for policymakers. To this end, international organizations like the IMF and the OECD regularly publish current account forecasts. However, Batchelor (2001) and Blix et al. (2001) show that international organizations provide less accurate forecasts compared to the private consensus forecast. This suggests that private sector forecasts should be taken into account when assessing future current account developments. A number of studies analyze the impact of private sector forecasts on the financial market. For example, Nickel et al. (2009) show that government bond yields respond to forecasts of country fundamentals. Prati and Sbracia (2010) find that currency crises can be provoked by changes in particular forecasts, such as current account forecasts. They show that speculation in the foreign exchange market is linked to uncertainty measured by the dispersion within the Consensus Economic Forecast Poll. An interesting question is whether the dispersion of current account forecasts solely reflects uncertainty about the countries fundamentals or whether the heterogeneity among forecasters is due to strategic or irrational behavior. Therefore, the aim of this paper is to analyze whether current account forecasts provide valuable information about future developments.

To the best of our knowledge, this paper is the first to study private sector current account forecasts. To this end, we use data from the Consensus Economics Forecast Poll to explore the characteristics of more than 65, 000 private sector forecasts of the current account for the euro area and G7 countries. In particular, we study the rationality, heterogeneity, and accu- 
racy of these forecasts. In addition to the test of traditional unbiasedness and orthogonality criteria for forecast rationality, we also shed some light on questions about herding behavior of forecasters.

\section{The Data}

We analyze survey data for the euro area and the G7 countries compiled by the Consensus Economics Forecast Poll on a monthly basis. In this survey, professional forecasters are regularly asked to submit their forecasts of several financial and macroeconomic variables, including GDP growth, private consumption, investment and the current account balance. Our data cover forecasts for the G7 countries for the period October 1989 to December 2009 and forecasts for the euro area for the period December 2002 through December 2009. The forecasters participating in the survey work with institutions such as investment banks, large international corporations, economic research institutes, and universities in the euro area or a G7 country. The number of forecasters of a particular country varies between 37 (Canada) and $68(\mathrm{UK}){ }^{1}$

In comparison with other survey data, the data of Consensus Economics Forecast Poll have the advantage that the participants forecast the level of macroeconomic variables and not just the direction of the annual year-on-year change. Another interesting feature of the Consensus Economics data is that not only the individual forecasts are published, but also the corresponding name of the forecasting institution. Thus, an evaluation of the accuracy of a particular institution's forecast is relatively easy to conduct so that participating in the survey can affect the reputation of the institution with respect to its forecasting activities. Finally, the Consensus Economics survey data contain forecasts for different forecast horizons, that is, for the current 
year and the next year. We can, thus, analyze short-term forecasts and medium-term forecasts.

Insert Table 1 about here.

Table 1 provides summary statistics of the monthly survey data and the actual annual values. Over the sample period, the forecasters expected on average a current account surplus of about $€ 30$ billion for Germany which is close to the actual average value of about $€ 34$ billion. This also applies to a number of other countries in the sample. For Japan, for instance, the expected current account surplus was close to $¥ 13$ trillion while the actual value was somewhat above $¥ 12$ trillion. However, this does not necessarily mean that the forecasts were accurate or rational.

In order to examine the time-series dimension and the cross-sectional dimension of the survey data, Figure 1 plots time series of (i) the cross-sectional mean values of the short-term current account forecasts (dashed lines), (ii) the actual current account balance (solid lines), and, (iii) the cross-sectional heterogeneity of forecasts as measured by the cross-sectional range of forecasts (shaded areas). The vertical distance between the dashed line and the solid line can be interpreted as the cross-sectional forecast error.

Insert Figure 1 about here.

These cross-sectional mean values move in tandem with the respective actual values, at least as far as end-of-year values are concerned. These results are intuitive because forecast accuracy should increase as the forecast horizon decreases. Another important information is that the cross-sectional heterogeneity of forecasts is substantial, especially during and in the aftermath of the financial crisis in 2008/2009. For instance, in April 2009, the forecasts of the U.S. current account deficit for 2009 range 
between $\$ 250$ billion and $\$ 625$ billion indicating a substantial degree of uncertainty among the forecasters. In this respect, forecasts of the current account resemble forecasts of, for example, exchange rates. ${ }^{2}$ To the best of our knowledge, the cross-sectional heterogeneity of the current account has not yet been documented in the literature. Given this heterogeneity, the following sections study in more detail individual forecasts of the current account.

\section{Rationality of Heterogeneous Forecasts}

Building on earlier research by Ito (1990), MacDonald and Marsh (1996), and Elliott and Ito (1999), we use two widely applied criteria to study rationality of heterogeneous forecasts: the criterion of unbiasedness of forecasts and the criterion of orthogonality of forecasts. In order to explore whether heterogeneous forecasts represent unbiased predictors of the future current account balance, we use the following regression model:

$C A_{t+k}=\alpha+\beta E_{i, t}\left[C A_{t+k}\right]+\epsilon_{i, t+k}$,

where $C A_{t+k}{ }^{3}$ denotes the actual current account balance in period $t+k$ and $E_{i, t}\left[C A_{t+k}\right]$ denotes the current account forecast for period $t+k$ made by forecaster $i$ in period $t$. In addition, $\epsilon_{i, t+k}$ denotes an error term. Forecasts are unbiased if $\alpha=0$ and $\beta=1$. If forecasts satisfy the unbiasedness criterion, forecasts are not necessarily accurate, but forecast errors do not show any systematic pattern.

The estimation results for each individual country, the euro area, and the pooled G7 countries are summarized in Table 2. They indicate that the constant term $\alpha$ is not significantly different from zero only in the cases of 
Canada, Germany (short-term) and Canada, France, Japan (medium term). In all the other cases, it is either significantly positive (Germany for the medium-term, France, Japan, the U.S. and G7 for the short-term) or significantly negative (Italy, UK, euro area, the U.S., and G7 for the medium-term, Italy, UK, and the euro area for the short-term). The slope coefficient $\beta$ is significantly different from unity in all cases and for both forecast horizons, except for Germany for the medium-term. Provided that all $\beta$ coefficients are positive, the results indicate that forecasters correctly forecast whether the current account balance shows a surplus or a deficit. For short-term forecasts, the slope coefficient for almost all countries is significantly closer to unity than the slope coefficient that is estimated for medium-term forecasts, reflecting that the forecast accuracy is higher with respect to the current year than the next year. Given that the constant term $\alpha$ is significantly different from zero and the slope coefficient $\beta$ is different from unity in nearly all cases, the hypothesis of unbiasedness of forecasts has to be rejected. ${ }^{4}$

Insert Table 2 about here.

The orthogonality criterion concerns the question whether heterogeneous forecast errors are uncorrelated with information available to forecasters at the time they form their expectations. In order to assess the individual information set of forecasters, we use the institutions' forecasts of other macroeconomic variables. This research strategy is applicable because the Consensus Economics Forecast Poll publishes the current account forecasts along with several forecasts of other macroeconomic variables, such as the GDP growth rate, the growth rate of private consumption and the growth rate of investment. Because modern economic theory views current account imbalances as an outcome of intertemporal consumption, and investment choices, our research strategy formalizes the idea that GDP growth, private consumption, and investment are major determinants of the current account (Sachs, 1981; Obstfeld and Rogoff, 1994; Freund, 2005). Then, orthogonality implies that 
current account forecasts should be tightly linked to contemporaneous forecasts of these macroeconomic variables. By the same token this means that the forecast error and contemporaneous forecasts of these macroeconomic variables should be uncorrelated. Accordingly, we estimate the following regression model for the forecast error:

$C A_{t+k}-E_{i, t}\left[C A_{t+k}\right]=\alpha+\beta E_{i, t}\left[G D P_{t+k}\right]+\gamma E_{i, t}\left[C_{t+k}\right]+\delta E_{i, t}\left[I_{t+k}\right]+\epsilon_{i, t+k}$,

where $E_{i, t}\left[G D P_{t+k}\right]$ denotes the expected GDP growth for period $t+k$ made by forecaster $i$ in period $t$. Accordingly $E_{i, t}\left[C_{t+k}\right]$ and $E_{i, t}\left[I_{t+k}\right]$ represent the expected private consumption and investment growth rates, respectively. The orthogonality criterion is satisfied if the parameter restriction $\alpha=\beta=\gamma=\delta=0$ cannot be rejected. Table 3 summarizes the estimation results. Although the scaling in equation (2) differs between the variables, the interpretation is straight forward: For instance, the value of the coefficient $\delta$ of $2.0(0.11)$ for the United States (Japan) reflects that the actual current account is higher than expected by $\$ 2.0$ billion ( $¥ 0.11$ trillion) if a forecaster expects a one percent increase in real domestic investment. Hence, the forecast error is correlated with the information set of the forecasters. Indeed, for nearly all countries and time horizons, the orthogonality condition can be rejected. This also applies when we pool all G7 countries and express the current account forecasts as ratios of actual GDP. The latter is useful, since the current account forecasts are denominated in different currencies. The coefficient $\gamma$ of about -.48 implies that if the forecasters expect the real growth rate to increase by one percentage point, the expected current account in terms of GDP ratio is lower by .48 percentage points than the actual ratio. The orthogonality restriction can also be rejected for the pooled G7 countries. Only for the UK and France (short-term), the orthogonality condition cannot be rejected. Interestingly, the relatively low fit of equation (2) indi- 
cates that the orthogonality restriction imposes a too strong restriction on the rationality of the current account forecasts. However, the relatively low fit also indicates that other factors, might influence the forecast error. For instance, Pierdzioch et al. (2010) show that the forecast error in the housing market is correlated with boom and bust cycles.

Insert Table 3 about here.

In sum, our results indicate that current account forecasts do not satisfy traditional criteria for unbiasedness and orthogonality. Since the forecast horizon decreases over the course of the year, the forecast error might be serial correlated. To check for robustness, we use forecasts published only in a specific month (e.g. January), which eliminates the serial correlation problem. The results of a specific-month analysis are not qualitatively different and are available upon request. Thus, our estimation results indicate that the hypothesis of rationality of forecasts can be rejected when traditional rationality criteria are applied. An explanation for the biasedness of current account forecasts can be that forecasters tend to herd or anti-herd. This could mean that they do not have the incentive to publish an accurate forecast but rather announce strategic forecasts. The next section investigates whether current account forecasters follow such behavior.

\section{A Test for Herding and Anti-Herding}

The fact that the number of analysts participating in the Consensus Economics Forecast Poll is quite large raises the question whether an individual forecaster is influenced by the forecasts of others, i.e., whether there is any herding or anti-herding behavior among them. ${ }^{5}$ Bernhardt et al. (2006) suggest an empirical test for herding or anti-herding that can be applied to our question as well. This involves studying the relationship between 
individual forecasts, the mean of the cross-sectional forecasts, and the actual current account. The test is based on the following considerations. With new information arriving, every forecaster combines all available information in order to update his forecast and to form a posterior distribution over current account balances. The mean of this distribution is the forecaster's best estimate of the current account and represents his unbiased forecast. Herding occurs when forecasters, being aware of the consensus forecast, place their forecast closer to the consensus than they would have done otherwise. In this case, forecasters bias a forecast away from their best estimate and towards the consensus forecast. Likewise, anti-herding occurs when forecasters bias their forecasts further away from the consensus than they would have done otherwise. Our finding of significant cross-sectional heterogeneity of forecasts in sections 2 and 3 could suggest that anti-herding is particularly prevalent among analysts participating in the Consensus Economics Forecast Poll.

If an analyst issues his best estimate of the current account as his forecast, he submits an unbiased forecast. In this case, he is not influenced by the consensus forecast of the participating analysts. We use the previous-month mean forecast as the consensus forecast, because the current-month mean forecast is not available to the forecasters. ${ }^{6}$ If an analyst does not herd or anti-herd and, hence, issues an unbiased forecast, i.e., his best estimate, the probability that his forecast $E_{i, t}\left[C A_{t+k}\right]$ exceeds (falls short of) the actual current account, $C A_{t+k}$, is equal to 0.5 , both unconditionally, and conditional on anything in the information set available to the forecaster, including the average forecast of all individual forecasters of the previous month, $\bar{E}_{t-1}\left[C A_{t+k}\right]$.

On this basis, the test for the herding or anti-herding behavior of forecasts, as proposed by Bernhardt et al. (2006), can be applied as follows: Under 
the null hypothesis of no herding and no anti-herding, the conditional probability, $P$, that a forecast of the current account overshoots (undershoots) the actual current account is 0.5, regardless of the consensus forecast. Accordingly, the conditional probability of overshooting the actual current account, given that the forecast is higher than the consensus forecast, is

$P\left(C A_{t+k}<E_{i, t}\left[C A_{t+k}\right] \mid E_{i, t}\left[C A_{t+k}\right]>\bar{E}_{t-1}\left[C A_{t+k}\right], C A_{t+k} \neq E_{i, t}\left[C A_{t+k}\right]\right)=0.5$.

Likewise the conditional probability of undershooting the actual current account, given that the forecast is smaller than the consensus forecast, is

$P\left(C A_{t+k}>E_{i, t}\left[C A_{t+k}\right] \mid E_{i, t}\left[C A_{t+k}\right]<\bar{E}_{t-1}\left[C A_{t+k}\right], C A_{t+k} \neq E_{i, t}\left[C A_{t+k}\right]\right)=0.5$.

The two conditional probabilities, thus, average 0.5. This is not the case under the alternative hypothesis of herding or anti-herding. If a forecaster herds and, thus, biases his forecast towards the consensus forecast, the forecast will be located between the unbiased private forecast and the consensus forecast. In the case that the forecast exceeds the consensus forecast, the conditional probability of overshooting the actual current account is smaller than 0.5. Similarly, if the forecast falls short of the consensus forecast, the conditional probability of undershooting is also smaller than 0.5. This means that

$P\left(C A_{t+k}<E_{i, t}\left[C A_{t+k}\right] \mid E_{i, t}\left[C A_{t+k}\right]>\bar{E}_{t-1}\left[C A_{t+k}\right], C A_{t+k} \neq E_{i, t}\left[C A_{t+k}\right]\right)<0.5$

and

$P\left(C A_{t+k}>E_{i, t}\left[C A_{t+k}\right] \mid E_{i, t}\left[C A_{t+k}\right]<\bar{E}_{t-1}\left[C A_{t+k}\right], C A_{t+k} \neq E_{i, t}\left[C A_{t+k}\right]\right)<0.5$.

If forecasters herd the average of the two conditional probabilities is smaller than 0.5. If forecasters anti-herd, in contrast, the average of the two conditional probabilities is larger than 0.5 . In this case the forecast overshoots 
the unbiased private forecast of the current account in the direction away from the consensus forecast. This means that

$P\left(C A_{t+k}<E_{i, t}\left[C A_{t+k}\right] \mid E_{i, t}\left[C A_{t+k}\right]>\bar{E}_{t-1}\left[C A_{t+k}\right], C A_{t+k} \neq E_{i, t}\left[C A_{t+k}\right]\right)>0.5$

and

$P\left(C A_{t+k}>E_{i, t}\left[C A_{t+k}\right] \mid E_{i, t}\left[C A_{t+k}\right]<\bar{E}_{t-1}\left[C A_{t+k}\right], C A_{t+k} \neq E_{i, t}\left[C A_{t+k}\right]\right)>0.5$.

The test statistic, $S$, is defined as the average of the sample estimates of the conditional probabilities used in Equations (5) - (8). Bernhardt et al. (2006) show that the test statistic, $S$, has an asymptotic normal distribution and is robust to various problems arising in the case of, e.g. correlated forecast errors, market-wide shocks, and optimism or pessimism among forecasters. It is this averaging that makes the test robust under the null hypothesis. For example, "bubble-like" swings in the current account in 2008/2009 may give rise to a preponderance of positive unexpected market-wide shocks to the current account. Such shocks raise (lower) the probability that the subsequently realized current account exceeds (falls short of) forecasts, given any conditioning information, but leave the average of the conditional probabilities unaffected under the null hypothesis. Market-wide shocks and the resulting positive cross-correlation of forecast errors do not bias the mean of the $S$ statistic but only reduce its variance below the one obtained in the case of zero cross-correlation of forecast errors. In other words, the test statistic $S$ is conservative, because positive unexpected shocks make it more difficult to reject the null hypothesis of unbiasedness when we should do so (Type II error).

Finally, it is relevant for our analysis to note that outliers and large disruptive events like the impact of the financial crisis 2008/2009 on the current account should have a minor effect on the conditional probabilities (i.e., empirical frequencies of events). The test statistic, $S$, is robust to such events. 


\section{$5 \quad$ Herding and Forecast Accuracy}

Table 4 summarizes the results of the herding test for the short-term and medium-term. For all countries, we find strong evidence of an anti-herding behavior of current account forecasters. For instance, for the U.S. (shortterm), we estimate a test statistic of $S=0.66$. With the standard deviation of 0.007 , the test statistic significantly exceeds its unbiased forecast value of 0.5. Since any year is surveyed in a total of 24 poll, i.e. in 12 shortterm forecasts and 12 medium-term forecasts, we combine short-term and medium-term forecasts, which increases the number of forecasts from 12 to 24 for every year. The results of the herding test reported in Table 5 indicate that the test statistic again significantly exceeds its unbiased forecast value of 0.5. Due to substantial fluctuations in the current account caused by the financial and economic turmoil of 2008/2009, we also analyze the temporal stability of our results by means of rolling-window estimates of the test statistic, $S$. The results, which are available upon request, are based on different window lengths, e.g., four and six years and indicate that the time-varying test statistic always significantly exceeds its unbiased forecast value of 0.5 . Hence, the anti-herding behavior of current account forecasts is not associated with a special period but is rather a phenomenon over the whole sample period. This supports the robustness of our results.

Our empirical results imply that forecasts tend to be biased and that most of the forecasts display anti-herd behavior. These two empirical results lead to the question of whether there is a systematic link between forecast accuracy and anti-herding of forecasters. In order to analyze this question, we proceed in two steps. First, we calculate the forecaster-specific Root Mean Squared Error $\left(\mathrm{RMSE}_{i}\right)$ as a measure of forecast accuracy for each forecaster over all forecasting periods covered by the Consensus Economics Forecast Poll data. Second, we compute the forecaster-specific herding 
coefficients $\left(S_{i}\right)$. Subsequently, we run the following regression in order to assess the significance of this correlation in more detail:

$R M S E_{i}=\alpha+\beta S_{i}+\epsilon_{i}$

Table 6 reports the estimation results. For most cases, there is a statistically significant positive correlation between anti-herding and forecast accuracy. Hence, forecasters who tend to herd have higher forecast accuracy than their colleagues who deliberately place their forecasts farther away from the consensus. ${ }^{7}$ For instance, the slope value for the short-term forecasts of about 137 in the case of Japan means that if the individual herding coefficient is smaller by about 0.01 , the forecast is on average closer to the actual value by about $¥ 1.37$ trillion.

Insert Tables 6 about here.

\section{Conclusions}

In this paper, we use monthly data from the Consensus Economics Forecast Poll for the euro area and the G7 countries to analyze the properties of current account forecasts. Given the significant cross-sectional heterogeneity of forecasts, our analysis of more than 65,000 individual forecasts provides interesting results on how forecasters arrive at their forecasts.

Our main results can be summarized as follows: First, current account forecasts do not satisfy traditional unbiasedness and orthogonality criteria for forecast rationality. Second, anti-herding behavior can be observed among forecasters. This result is robust with respect to different time horizons and countries examined. Third, the cross-sectional heterogeneity of forecasts with regard to anti-herding is associated with cross-sectional heterogeneity in forecast accuracy. 
Our results do not only provide insight into how forecasters form their expectations, but can also be valuable for economic agents. Policymakers, for instance, consider current account forecasts of the private sector in their economic analyses, as these contain important information on the market perception with respect to the external developments of a country. In particular, foreign exchange market participants might base their trading decisions on current account forecasts. However, our results demonstrate that economic agents who use private sector forecasts should be aware of the issues concerning rationality, heterogeneity, herding and accuracy of current account forecasts. Whether international organizations, such as the IMF and the OECD, also publish strategic forecasts provides an interesting field for future research. 


\section{References}

Batchelor, Roy, "How useful are the forecasts of intergovernmental agencies? - The IMF and OECD versus the consensus," Applied Economics 33 (2001): 225-235.

Benassy-Quere, Agnès, Larribeau, Sophie and Ronald MacDonald, "Models of Exchange Rate Expectations: How Much Heterogeneity?," Journal of International Financial Markets, Institutions and Money 13 (2) (2003): 113-136.

Berger, Helge, Kalyvitis, Sarantis and Thomas Moutos, "Global Economic Imbalances: Prospects and Remedies", Review of International Economics 16 (3) (2008): 478-610.

Bernhardt, Dan, Campello, Murillo and Edward Kutsoati, "Who Herds?" Journal of Financial Economics 80 (2006): 657-675.

Blix, Marten, Wadefjord, Joachim, Wienecke, Ulrika and Adahl Martin, "How good is the forecasting performance of major institutions?," Sveriges Riksbank Economic Review Economic 3 (2001): 38-68.

Caballero, Ricardo, Farhi, Emmanuel and Pierre-Olivier Gourinchas, "Financial Crash, Commodity Prices and Global Imbalances," Brookings Papers on Economic Activity 2 (2008): 1-55.

Chinn, Menzie D. and Hiro Ito, "Global Current Account Imbalances: American Fiscal Policy versus East Asian Savings", Review of International Economics 16 (3) (2008): 479-498.

De Haan, Leo, Schokker, Hubert and Anastassia Tcherneva, "What Do Current Account Reversals in the OECD Countries Tell Us About the U.S. Case?," The World Economy 31 (2) (2008): 286-311. 
Eijffinger, Sylvester and Benedikt Goderis, "Currency Crises, Monetary Policy and Corporate Balance Sheets", German Economic Review 8 (3) (2007): 309-343.

Engler, Philipp, Fidora, Michael and Christian Thimann, "External Imbalances and the US Current Account: How Supply-Side Changes Affect an Exchange Rate Adjustment", Review of International Economics 17 (5) (2009): 927-941.

Elliott, Graham and Takatoshi Ito, "Heterogeneous Expectations and Tests of Efficiency in the Yen/Dollar Forward Exchange Rate Market," Journal of Monetary Economics 43 (1999): 435-456.

Freund, Caroline, "Current Account Adjustment in Industrialized Countries," Journal of International Money and Finance 24 (8) (2005): 1278-1298.

Ito, Takatoshi, "Foreign Exchange Expectations: Micro Survey Data," American Economic Review 80 (1990): 434-449.

Lakonishok, Josef, Shleifer Andrei and Robert W. Vishny, "The Impact of Institutional Trading on Stock Prices," Journal of Financial Economics 32 (1992): 23-43.

Laster, David, Bennett, Paul and In Sun Geoum, "Rational Bias in Macroeconomic Forecasts," Quarterly Journal of Economics 114 (1) (1999): 293-318.

MacDonald, Ronald and Ian W. Marsh, "Currency Forecasters are Heterogeneous: Confirmation and Consequences," Journal of International Money and Finance 15 (1996): 227-239. 
McKinnon, Ronald, "The International Dollar Standard and the Sustainability of the U.S. Current Account Deficit," Brookings Papers on Economic Activity 1 (2001): 665-685.

Milesi-Ferreti, Gian Maria and Assaf Razin, Current Account Reversals and Currency Crises: Empirical Regularities, in: Krugman, Paul (ed.) "Currency Crisis," National Bureau of Economic Research (2000): 285326.

Nickel, Christiane, Rother, Philipp and Jan-Christoph Rülke, "Fiscal variables and bond spreads: Evidence from eastern European countries and Turkey," ECB working paper 1101 (2009).

Obstfeld Maurice and Kenneth Rogoff, "The Intertemporal Approach to the Current Account," National Bureau of Economic Research Working Paper 4893 (1994).

Pierdzioch, Christian, Rülke, Jan and Georg Stadtmann, "Housing Starts in Canada, Japan and the United States: Do Forecasters Herd?," Journal of Real Estate Economics and Finance, (2010 forthcoming).

Prati, Alessandro and Massimo Sbracia, "Uncertainty and currency crises: Evidence from survey data," Journal of Monetary Economics, (2010 forthcoming).

Sachs, Jeffrey, "The Current Account and Macroeconomic Adjustment in the 1970s," Brookings Papers on Economic Activity 1 (1981). 


\section{Notes}

${ }^{1} \mathrm{~A}$ complete list of participants is available upon request.

${ }^{2}$ Cross-sectional heterogeneity of forecasts of exchange rates has been widely documented in the recent literature (see, e.g., Benassy-Quere et al., 2003).

${ }^{3}$ The index $k$ denotes the forecast horizon expressed in months (with $k=12,11, \ldots, 1$ for short-term forecasts, and $k=24,23, . ., 13$ for medium-term forecasts).

${ }^{4}$ Violation of the traditional criteria does not necessarily imply that forecasts are irrational, but could indicate, for example, that forecasters do not have a quadratic loss function. Laster et al. (1999) lay out a model of forecaster anti-herding in which forecasters do not have a traditional quadratic loss function.

${ }^{5}$ Our analysis concerns the cross-sectional herding or anti-herding of forecasters. In the empirical literature, researchers use the term "herding" to characterize the time-series properties of forecasts (Lakonishok et al., 1992). Our usage of the term herding, thus, should not be confused with the terminology used by other researchers who utilize the term herding to describe, for example, destabilizing trend-extrapolative forecasts in a time series context.

${ }^{6}$ To identify herding for, e.g., the short-term January forecasts with the forecast horizon being twelve months, we use the consensus of the medium-term forecast of December which has a forecast horizon of thirteen months. Hence, we combine short-term and mediumterm forecasts in this case. However, we drop the medium-term January forecasts from the analysis, as a reference value is not available to us.

${ }^{7}$ The higher accuracy of forecasts of those who herd as compared to forecasts of those who anti-herd does not imply that the former are more "successful" than the latter. Forecaster success, when viewed from the perspective of forecasters, depends on the forecaster's loss function and not necessarily on the forecast accuracy. Anti-herding, thus, can be a rational strategy even if it leads to lower forecast accuracy, as some forecasters might put more weight on publicity resulting from submitting more extreme forecasts than on accuracy (Bernhardt et al., 2006; Laster et al., 1999). 
Table 1: Summary Statistics for the Current Account Balance

\begin{tabular}{|c|c|c|c|c|c|c|c|c|}
\hline Short-Term & $\begin{array}{l}\text { Canada } \\
\text { bn. C\$ }\end{array}$ & $\begin{array}{c}\text { France } \\
\text { bn. } €\end{array}$ & $\begin{array}{c}\text { Germany } \\
\text { bn. } €\end{array}$ & $\begin{array}{l}\text { Italy } \\
\text { bn. } €\end{array}$ & $\begin{array}{l}\text { Japan } \\
\text { tr. } ¥\end{array}$ & $\begin{array}{l}\text { UK } \\
\text { bn. } £\end{array}$ & $\begin{array}{l}\text { U.S. } \\
\text { bn. } \$\end{array}$ & $\begin{array}{c}\text { Euro Area } \\
\text { bn. } €\end{array}$ \\
\hline Mean of Forecast & -1.29 & 4.77 & 29.86 & -3.19 & 12.85 & -16.73 & -362.37 & 4.08 \\
\hline Standard Deviation of Forecasts & $(.37)$ & $(.36)$ & $(.72)$ & $(.41)$ & $(.08)$ & $(.16)$ & $(3.92)$ & $(.99)$ \\
\hline Mean of Actual Current Account & -0.32 & 5.74 & 34.39 & -8.04 & 12.25 & -19.55 & -348.90 & -15.30 \\
\hline No. of Observations & 3,650 & 3,597 & 5,993 & 2,856 & 4,509 & 6,848 & 4,661 & 1,886 \\
\hline No. of Periods & 245 & 245 & 245 & 245 & 245 & 245 & 245 & 85 \\
\hline No. of Forecasters & 37 & 39 & 55 & 38 & 55 & 68 & 65 & 38 \\
\hline Medium-Term & Canada & France & Germany & Italy & Japan & UK & U.S. & Euro Area \\
\hline Mean of Forecast & -0.94 & 4.01 & 32.97 & -2.18 & 13.17 & -17.69 & -371.61 & 9.34 \\
\hline Standard Deviation of Forecasts & $(.34)$ & $(.39)$ & $(.73)$ & $(.42)$ & $(.10)$ & $(.17)$ & $(4.05)$ & $(.98)$ \\
\hline Mean of Actual Current Account & -0.32 & 5.74 & 34.39 & -8.04 & 12.25 & -19.55 & -348.90 & -15.30 \\
\hline No. of Observations & 3,615 & 3,135 & 5,505 & 2,648 & 3,529 & 6,530 & 4,294 & 1,612 \\
\hline No. of Periods & 245 & 245 & 245 & 245 & 245 & 245 & 245 & 85 \\
\hline No. of Forecasters & 37 & 39 & 55 & 38 & 55 & 68 & 65 & 38 \\
\hline
\end{tabular}

Table 2: Test for Unbiasedness of Forecasts

\begin{tabular}{|c|c|c|c|c|c|c|c|c|c|}
\hline Short-Term & Canada & France & Germany & Italy & Japan & UK & U.S. & G7 & Euro Area \\
\hline \multirow[t]{2}{*}{$\alpha$} & -.27 & $1.83^{* *}$ & .14 & $-4.68^{* *}$ & $.02 *$ & $-7.77^{* *}$ & $6.46^{* *}$ & $.74^{*}$ & $-14.60^{* *}$ \\
\hline & $(.46)$ & $(.01)$ & $(.67)$ & $(.50)$ & $(.01)$ & $(.45)$ & $(2.13)$ & $(.26)$ & $(3.29)$ \\
\hline \multirow[t]{2}{*}{$\beta$} & $.87^{* *}$ & $.92^{* *}$ & $1.09 * *$ & $.96^{* *}$ & $.92^{* *}$ & $.62^{* *}$ & $.96^{* *}$ & $.95^{* *}$ & $.74^{* *}$ \\
\hline & $(.02)$ & $(.02)$ & $(.02)$ & $(.02)$ & $(.01)$ & $(.03)$ & $(.01)$ & $(.00)$ & $(.05)$ \\
\hline$H_{0}: \beta=1$ & .00 & .00 & .00 & .07 & .00 & .00 & .00 & .00 & .00 \\
\hline$H_{0}: \alpha=0 \& \beta=1$ & .00 & .00 & .00 & .00 & .00 & .00 & .00 & .00 & .00 \\
\hline$R^{2}$ & .77 & .83 & .88 & .82 & .90 & .53 & .97 & .98 & .25 \\
\hline No. of Observations & 3,650 & 3,789 & 5,993 & 2,856 & 4,509 & 6,848 & 4,661 & 32,338 & 1,886 \\
\hline No. of Periods & 245 & 245 & 245 & 245 & 245 & 245 & 245 & 245 & 85 \\
\hline No. of Forecasters & 37 & 39 & 55 & 38 & 55 & 68 & 65 & 357 & 36 \\
\hline \multicolumn{10}{|l|}{ Medium-Term } \\
\hline \multirow[t]{2}{*}{$\alpha$} & -.09 & 1.45 & $4.81^{* *}$ & $-7.99^{* *}$ & -.01 & $-7.84^{* *}$ & $-27.63^{* *}$ & $-1.35^{*}$ & $-29.70^{* *}$ \\
\hline & $(.90)$ & $(.03)$ & $(1.41)$ & $(.87)$ & $(.03)$ & $(.51)$ & $(4.74)$ & $(.50)$ & $(4.79)$ \\
\hline \multirow[t]{2}{*}{$\beta$} & $.69^{* *}$ & $.83^{* *}$ & $.98^{* *}$ & $.89^{* *}$ & $.63^{* *}$ & $.58^{* *}$ & $.90 * *$ & $.94^{* *}$ & $.68^{* *}$ \\
\hline & $(.03)$ & $(.05)$ & $(.04)$ & $(.04)$ & $(.02)$ & $(.03)$ & $(.01)$ & $(.01)$ & $(.10)$ \\
\hline$H_{0}: \beta=1$ & .00 & .00 & .59 & .00 & .00 & .00 & .00 & .00 & .00 \\
\hline$H_{0}: \alpha=0 \& \beta=1$ & .00 & .00 & .00 & .00 & .00 & .00 & .00 & .00 & .00 \\
\hline$R^{2}$ & .37 & .58 & .62 & .61 & .58 & .42 & .88 & .94 & .13 \\
\hline No. of Observations & 3,615 & 3,296 & 5,505 & 2,648 & 3,529 & 6,530 & 4,294 & 29,275 & 1,612 \\
\hline No. of Periods & 245 & 245 & 245 & 245 & 245 & 245 & 245 & 245 & 85 \\
\hline No. of Forecasters & 37 & 39 & 55 & 38 & 55 & 68 & 65 & 357 & 36 \\
\hline
\end{tabular}


Table 3: Test for Orthogonality of Forecasts

\begin{tabular}{|c|c|c|c|c|c|c|c|c|c|}
\hline Short-Term & Canada & France & Germany & Italy & Japan & UK & U.S. & G7 & Euro Area \\
\hline$\alpha$ & $\begin{array}{c}-2.62^{* *} \\
(.81)\end{array}$ & $\begin{array}{c}.56 \\
(1.18)\end{array}$ & $\begin{array}{c}8.73^{* *} \\
(1.21)\end{array}$ & $\begin{array}{c}-5.14^{* *} \\
(.78)\end{array}$ & $\begin{array}{c}-1.42^{* *} \\
(.14)\end{array}$ & $\begin{array}{c}-2.96^{* *} \\
(.62)\end{array}$ & $\begin{array}{c}27.51^{* *} \\
(4.09)\end{array}$ & $\begin{array}{l}-.02 \\
(.24)\end{array}$ & $\begin{array}{c}-54.29^{* *} \\
(7.94)\end{array}$ \\
\hline$\beta$ & $\begin{array}{c}2.43^{* *} \\
(.37)\end{array}$ & $\begin{array}{l}-.48 \\
(.58)\end{array}$ & $\begin{array}{l}-.09 \\
(.78)\end{array}$ & $\begin{array}{c}5.65^{* *} \\
(.61)\end{array}$ & $\begin{array}{l}-.95^{*} \\
(.12)\end{array}$ & $\begin{array}{l}.33 \\
(.40)\end{array}$ & $\begin{array}{c}-17.25^{* *} \\
(2.95)\end{array}$ & $\begin{array}{l}.11 \\
(.15)\end{array}$ & $\begin{array}{l}-3.20 \\
(6.39)\end{array}$ \\
\hline$\gamma$ & $\begin{array}{c}-1.79^{* *} \\
(.33)\end{array}$ & $\begin{array}{l}.58 \\
(.76)\end{array}$ & $\begin{array}{c}-6.56^{* *} \\
(.72)\end{array}$ & $\begin{array}{c}-2.88^{* *} \\
(.51)\end{array}$ & $\begin{array}{c}1.23 * * \\
(.12)\end{array}$ & $\begin{array}{l}.50 \\
(.30)\end{array}$ & $\begin{array}{c}9.94^{* *} \\
(2.49)\end{array}$ & $\begin{array}{c}-.48^{* *} \\
(.15)\end{array}$ & $\begin{array}{c}43.67^{* *} \\
(7.71)\end{array}$ \\
\hline$\delta$ & $\begin{array}{l}.38^{* *} \\
(.07) \\
\end{array}$ & $\begin{array}{l}.28 \\
(.16) \\
\end{array}$ & $\begin{array}{l}.47^{*} \\
(.22)\end{array}$ & $\begin{array}{c}-1.91^{*} \\
(.22)\end{array}$ & $\begin{array}{l}.11^{* *} \\
(.02)\end{array}$ & $\begin{array}{l}-.08 \\
(.11) \\
\end{array}$ & $\begin{array}{c}2.00^{* *} \\
(.33)\end{array}$ & $\begin{array}{l}.16^{* *} \\
(.03)\end{array}$ & $\begin{array}{c}-7.63^{* *} \\
(2.52) \\
\end{array}$ \\
\hline$H_{0}: \alpha=\beta=\gamma=\delta=0$ & .00 & .53 & .00 & .00 & .00 & .10 & .00 & .00 & .00 \\
\hline$R^{2}$ & .18 & .01 & .09 & .16 & .11 & .01 & .04 & .01 & .08 \\
\hline No. of Observations & 3,650 & 3,597 & 5,993 & 2,856 & 4,509 & 6,848 & 4,661 & 31,574 & 1,886 \\
\hline No. of Periods & 245 & 245 & 245 & 245 & 245 & 245 & 245 & 245 & 85 \\
\hline No. of Forecasters & 37 & 39 & 55 & 38 & 55 & 68 & 65 & 357 & 36 \\
\hline \multicolumn{10}{|l|}{ Medium-Term } \\
\hline$\alpha$ & $\begin{array}{l}-6.60^{*} \\
(2.79)\end{array}$ & $\begin{array}{c}.53 \\
(2.12)\end{array}$ & $\begin{array}{c}22.30^{* *} \\
(5.02)\end{array}$ & $\begin{array}{c}-9.02^{* *} \\
(1.92)\end{array}$ & $\begin{array}{l}-2.31 \\
(.34)\end{array}$ & $\begin{array}{c}-3.21^{* *} \\
(1.18)\end{array}$ & $\begin{array}{c}78.81^{* *} \\
(9.82)\end{array}$ & $\begin{array}{c}.04 \\
(.64)\end{array}$ & $\begin{array}{c}20.09 \\
(11.76)\end{array}$ \\
\hline$\beta$ & $\begin{array}{l}4.05^{* *} \\
(1.49)\end{array}$ & $\begin{array}{l}3.99^{*} \\
(1.70)\end{array}$ & $\begin{array}{c}-15.21^{* *} \\
(3.29)\end{array}$ & $\begin{array}{c}16.09^{* *} \\
(1.62)\end{array}$ & $\begin{array}{l}.11 \\
(.25)\end{array}$ & $\begin{array}{l}.615 \\
(.60)\end{array}$ & $\begin{array}{c}9.94 \\
(8.02)\end{array}$ & $\begin{array}{l}.71^{*} \\
(.40)\end{array}$ & $\begin{array}{c}-43.55^{* *} \\
(12.65)\end{array}$ \\
\hline$\gamma$ & $\begin{array}{c}-4.52^{* * *} \\
(1.62)\end{array}$ & $\begin{array}{c}-6.58^{* *} \\
(1.53)\end{array}$ & $\begin{array}{c}-5.03^{*} \\
(2.07)\end{array}$ & $\begin{array}{c}-10.19^{* *} \\
(1.23)\end{array}$ & $\begin{array}{l}.97^{* *} \\
(.25)\end{array}$ & $\begin{array}{l}-.21 \\
(.52)\end{array}$ & $\begin{array}{c}-30.21^{* *} \\
(7.64)\end{array}$ & $\begin{array}{c}-1.85^{* *} \\
(.38)\end{array}$ & $\begin{array}{c}-13.07^{*} \\
(7.57)\end{array}$ \\
\hline$\delta$ & $\begin{array}{c}1.08^{* *} \\
(.20)\end{array}$ & $\begin{array}{c}1.22^{* *} \\
(.37)\end{array}$ & $\begin{array}{c}4.44^{* *} \\
(.75)\end{array}$ & $\begin{array}{c}-3.72 * * \\
(.56)\end{array}$ & $\begin{array}{l}-.00 \\
(.04)\end{array}$ & $\begin{array}{l}.52^{* *} \\
(.13)\end{array}$ & $\begin{array}{c}-3.22 * * \\
(1.24) \\
\end{array}$ & $\begin{array}{l}.47^{* *} \\
(.08) \\
\end{array}$ & $\begin{array}{c}17.73^{* * *} \\
(4.33)\end{array}$ \\
\hline$H_{0}: \alpha=\beta=\gamma=\delta=0$ & .00 & .00 & .00 & .00 & .00 & .42 & .00 & .00 & .00 \\
\hline$R^{2}$ & .06 & .05 & .08 & .17 & .09 & .03 & .08 & .01 & .08 \\
\hline No. of Observations & 3,615 & 3,135 & 5,505 & 2,648 & 3,529 & 6,530 & 4,294 & 28,538 & 1,612 \\
\hline No. of Periods & 245 & 245 & 245 & 245 & 245 & 245 & 245 & 245 & 85 \\
\hline No. of Forecasters & 37 & 39 & 55 & 38 & 55 & 68 & 65 & 357 & 36 \\
\hline
\end{tabular}

Note: This table shows estimation results based on the Newey-West estimator given in Equation (2) $C A_{t+k}-$ $E_{i, t}\left[C A_{t+k}\right]=\alpha+\beta E_{i, t}\left[G D P_{t+k}\right]+\gamma E_{i, t}\left[C_{t+k}\right]+\delta E_{i, t}\left[I_{t+k}\right]+\epsilon_{i, t+k}$. Robust standard errors are given in parentheses $\left.* *{ }^{*}\right)$ indicates significance at a 1 (5) percent significance level. To pool the G7 countries we express the current account forecasts in terms of GDP, i.e. we divided the current account forecast by the actual GDP and multiplied this ratio by 1000 for readers' convenience.

Table 4: Test for Herding

\begin{tabular}{|c|c|c|c|c|c|c|c|c|c|}
\hline Short-Term & Canada & France & Germany & Italy & Japan & UK & U.S. & G7 & Euro Area \\
\hline S-statistic & .579 & .637 & .621 & .597 & .679 & .627 & .662 & .601 & .685 \\
\hline Stand. Dev. & .008 & .008 & .007 & .010 & .007 & .006 & .007 & .004 & .012 \\
\hline Lower $99 \%$ & .557 & .615 & .604 & .572 & .660 & .611 & .642 & .592 & .654 \\
\hline Upper $99 \%$ & .600 & .658 & .638 & .621 & .699 & .643 & .681 & .610 & .715 \\
\hline \multicolumn{10}{|l|}{ Medium-Term } \\
\hline S-statistic & .616 & .585 & .576 & .574 & .674 & .648 & .652 & .536 & .611 \\
\hline Stand. Dev. & .009 & .009 & .007 & .010 & .008 & .006 & .008 & .004 & .013 \\
\hline Lower $99 \%$ & .594 & .562 & .559 & .548 & .652 & .632 & .632 & .526 & .579 \\
\hline Upper $99 \%$ & .638 & .608 & .594 & .600 & .696 & .664 & .673 & 546 & .644 \\
\hline
\end{tabular}

Note: $\overline{\text { The test statistic, } S \text {, is defined as the average of the sample estimates of the conditional probabilities given in }}$ Equations (5) - (8). If forecasters do not herd or anti-herd (null hypothesis), the test statistic assumes the value $S=0.5$. If forecasters herd, the test statistic assumes a value $S<0.5$. If forecasters anti-herd, the test statistic assumes value a $S>0.5$. The test statistic, $S$, has an asymptotic normal distribution.

Table 5: Test for Herding with Combined Short and Medium-Term Forecasts

\begin{tabular}{lccccccccc} 
& Canada & France & Germany & Italy & Japan & UK & U.S. & G7 & Euro Area \\
\hline S-statistic & .586 & .615 & .619 & .585 & .709 & .616 & .613 & .579 & .637 \\
Stand. Dev. & .007 & .007 & .006 & .008 & .006 & .005 & .006 & .003 & .010 \\
Lower 99\% & .567 & .596 & .605 & .564 & .690 & .602 & .596 & .572 & .610 \\
Upper 99\% & .605 & .633 & .634 & .606 & .724 & .630 & .630 & .587 & .664 \\
\hline
\end{tabular}

Note: The test statistic, $S$, is defined as the average of the sample estimates of the conditional probabilities given in Equations (5) - (8). If forecasters do not herd or anti-herd (null hypothesis), the test statistic assumes the value $S=0.5$. If forecasters herd, the test statistic assumes a value $S<0.5$. If forecasters anti-herd, the test statistic assumes value a $S>0.5$. The test statistic, $S$, has an asymptotic normal distribution. 
Table 6: Forecast Accuracy and Herding

\begin{tabular}{|c|c|c|c|c|c|c|c|c|c|}
\hline Short-Term & Canada & France & Germany & Italy & Japan & UK & U.S. & G7 & Euro Area \\
\hline \multirow[t]{2}{*}{$\alpha$} & 4.73 & 19.85 & $15.37^{* *}$ & $21.09^{*}$ & -46.33 & 2.32 & 8.14 & -7.00 & 22.98 \\
\hline & $(3.01)$ & $(36.74)$ & $(5.40)$ & $(8.66)$ & $(27.47)$ & $(2.42)$ & $(10.28)$ & $(7.94)$ & $(12.91)$ \\
\hline$\beta$ & $\begin{array}{l}10.70^{*} \\
(5.09)\end{array}$ & $\begin{array}{c}69.05 \\
(57.80)\end{array}$ & $23.41 * *$ & $\begin{array}{c}-6.53 \\
(14.48)\end{array}$ & $\begin{array}{c}136.72^{* * *} \\
(41.53)\end{array}$ & $10.39^{* *}$ & $\begin{array}{l}53.58^{* *} \\
(1568)\end{array}$ & $59.32^{* *}$ & $47.29^{*}$ \\
\hline$R^{2}$ & .13 & .01 & .13 & .01 & 21 & .11 & .16 & .07 & .14 \\
\hline Forecaster & 37 & 39 & 55 & 38 & 55 & 68 & 65 & 307 & 36 \\
\hline \multicolumn{10}{|c|}{ Medium-Term } \\
\hline \multirow[t]{2}{*}{$\alpha$} & 6.10 & $103.73^{* *}$ & $31.53^{* *}$ & $16.69^{*}$ & $60.67^{*}$ & $5.73^{*}$ & 29.48 & $35.82^{* *}$ & $44.80^{* *}$ \\
\hline & $(4.05)$ & $(32.02)$ & $(8.18)$ & $(7.15)$ & $(23.39)$ & $(2.37)$ & $(24.89)$ & $(9.81)$ & $(14.27)$ \\
\hline \multirow[t]{2}{*}{$\beta$} & $19.43^{* *}$ & -66.63 & $30.71^{*}$ & 15.21 & -33.57 & 6.67 & $84.09^{*}$ & 9.28 & 44.21 \\
\hline & $(6.63)$ & $(55.36)$ & $(14.31)$ & $(12.19)$ & $(34.51)$ & (3.65) & $(37.90)$ & $(15.63)$ & $(23.29)$ \\
\hline$R^{2}$ & .22 & .01 & .10 & .06 & .00 & .04 & .09 & .00 & .11 \\
\hline Forecaster & 37 & 39 & 55 & 38 & 55 & 68 & 65 & 286 & 36 \\
\hline
\end{tabular}


Figure 1: Expected and Actual Current Account Balance Canada

France
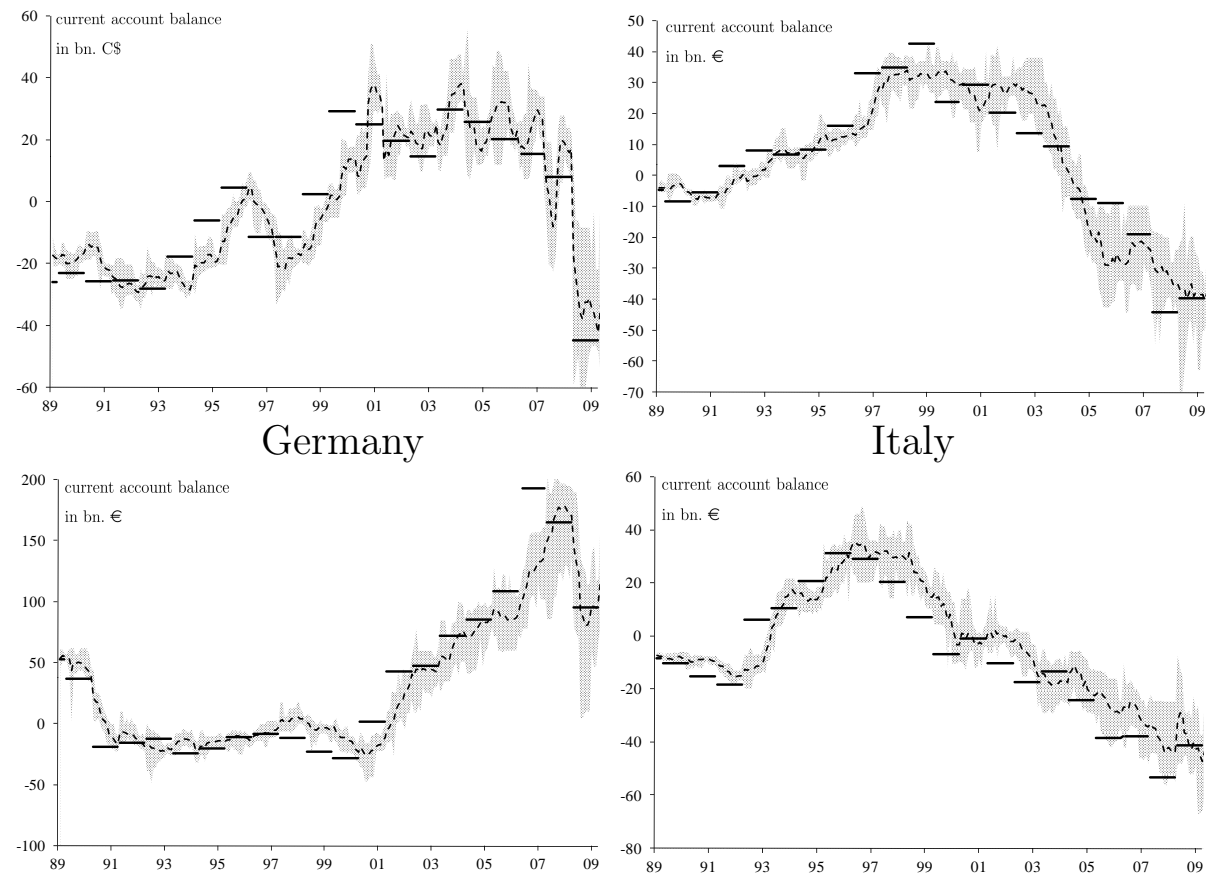

Japan
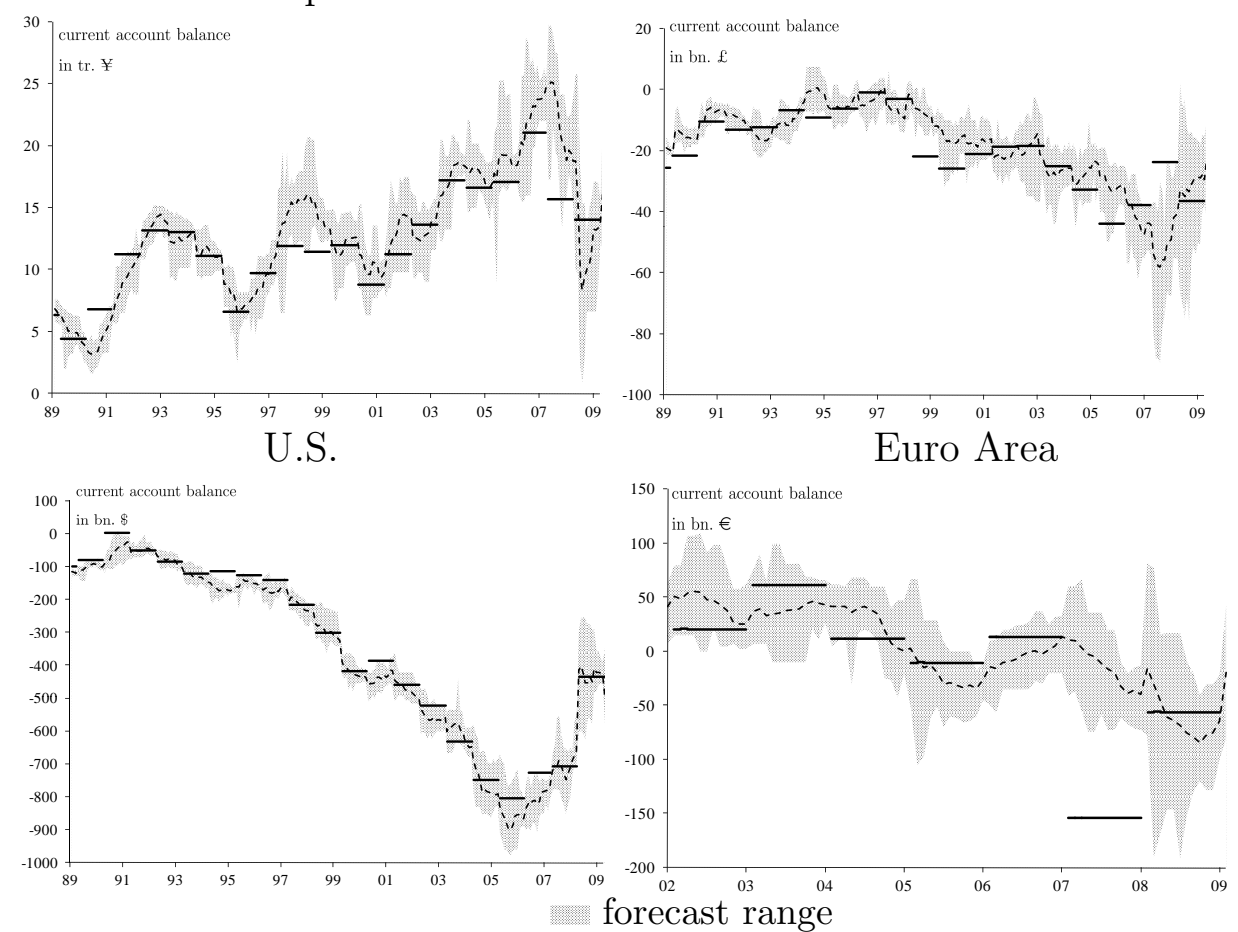

- consensus forecast, $\overline{E_{t}}\left[\mathrm{CA}_{t+k}\right]$

- actual current account balance, $\left(\mathrm{CA}_{t+k}\right)$

Notes: This figure shows the cross-sectional mean of the short-term current account forecasts (dashed line), the actual current account balance (solid line), and the forecast range (shaded area). The vertical distance between the expected and the actual current account reflects the forecast error. Actual current account balances are taken form the International Monetary Fund database. 